\title{
Effect of L-Carnitine used in regular exercise in elderly obesis rats
}

\author{
İbrahim Kubilay TÜRKAY1, Aynur BAŞALP1 \\ ${ }^{1}$ Mehmet Akif Ersoy University, Burdur, Turkey \\ Address Correspondence to I.K. TÜRKAY, Turkay, e-mail: kubilay.turk.ay@/hotmail.com
}

\begin{abstract}
The aim of this study was to investigate the effect of L-Caritine supplemented elderly rats on weight loss during 12 weeks. This experimental study was carried out on experimental animals in a scientific laboratory environment, under defined conditions and according to the method of application. Therefore, the model of the research is an experimental research model. In this study, 8 obese aged rats were used for 20 months. Approximately 70 years of human life is equivalent. The rats were given special cholesterol food for obesity. In the study, L-Carnitine was administered to the experimental group 3 times a week just before the exercise, with the daily dose of the sublingual fluid administered to the rats in a suitable dose $(1 \mathrm{gr} / \mathrm{kg})$. Before the exercise + L-Carnitine application, weight measurements of the rats were recorded at the beginning of the study (day 1), in the middle of the study (day 45) and finally at the end of the study (day 90). The "IBM SPSS Statistics 22 analiz package program was used to evaluate the statistical analysis of the study. Normal distribution assumptions were evaluated with KolmogorovSmirnov and Shapiro-Wilk tests. In the rare cases where the two tests are contradictory, the Kolmogorov-Smirnov test result, which is more preferred in small data sets, was used. Type 1 error margin for normality tests is taken as 0.05 . At the end of the study, it was determined that the weight of the old obese rats who used L-Carnitine together with the regular exercise for 12 weeks, both on the 45th and 90th days, was found.
\end{abstract}

Key words: Elderly obese, Rat, Regular exercise, L-carnitine, Effect

\section{INTRODUCTION}

Exercise is a structured, systematic, activity aimed at improving physical fitness, which is organized in order to improve the physical state of the individual. The effect of regular exercise on biochemical values has become a working area. At the same time, the method, severity and duration of the exercise are scientifically proven to differ in biochemical sense (2). There are two kinds of organism response to the effect of exercise. First; the one-off exercise is the acute exercise. The other type of response is systematic, regular exercise, which is a repetitive type of exercise that represents stability (4).

Obesity is derived from the word dolay1 obesiteus 'and is due to eating. Obesity as a result of unbalanced nutrition in children and adolescents; When the amount of energy taken with nutrients exceeds the amount of energy consumed by basal metabolism and bodily movement, it is a disease caused by accumulation of excess fat in the body (3). Obesity; diabetes, arteriosclerotic heart disease, hypertension, such as causing health problems, triglycerides are stored in excess of a disease (13).
Because of the extra weight in the physical activities of obese patients, cardiovascular and respiratory loading is larger than normal and their physical performance is seriously affected (12). In today's society, the level of knowledge about physical activity is insufficient, the importance of physical activity for health is not understood and the adoption of an increasingly sedentary lifestyle, increasing the prevalence of chronic diseases such as obesity, cardiovascular diseases, hypertension, diabetes, osteoporosis One of the reasons was (11). Obesity; diabetes, arteriosclerotic heart disease, hypertension, such as causing health problems, triglycerides are stored in excess of a disease (13). Obesity is a serious health problem that shortens life span and reduces the quality of life. Because of the extra weight in the physical activities of obese patients, cardiovascular and respiratory loading is larger than normal and their physical performance is seriously affected (12).

Carnitine palmitoyltransferase- 1 is a transmembrane protein located on the outer mitochondrial membrane, where it catalyzes the conversion of acyl-coenzyme A esters to acylcarnitine esters (7). Carnitine increases non- 
oxidative glucose excretion under euglycemic hyperinsulinemic conditions in both healthy individuals and type 2 diabetes, suggesting that 1carnitine enhances insulin action on glycogen storage (9). Carnitine administration improves insulin-induced glucose excretion, indicating that the metabolite is functioning in the interface between fatty acid metabolism and glucose metabolism (10).Human skeletal muscle oxidizes glucose and fatty acids to form ATP during physical exercise. These metabolites are derived from plasma, glycogen and triacylglycerol stores. The workload of working muscles determines the fuel that is partly consumed. During high-intensity short-term exercise (more than $75 \%$ of peak oxygen consumption), carbohydrates are the preferred fuel, while fatty acids are preferred as low-energy (less than $50 \%$ of maximum oxygen consumption) physical energy as a source of energy (8). . The increase in acetyl carnitine production during highintensity exercise was not constantly changed by carnitine supplementation before exercise (1). The aim of this study was to investigate the effect of LCarnitine on exercise on weight of young obese rats using L-Carnitine for 12 weeks.

\section{MATERIAL AND METHOD}

This study was carried out on experimental animals according to experimental research model in laboratory environment, under determined conditions and application method. This study was approved by the Local Ethics Committee of Mehmet Akif Ersoy University with the decision dated 02.08.2017 and numbered 312 (Date and number of documents: 08.08.2017-E.37983- Issue: 93773921-020).

In this study, 8 obese aged rat rats were used for 20 months. Approximately 70 years of human life is equivalent.

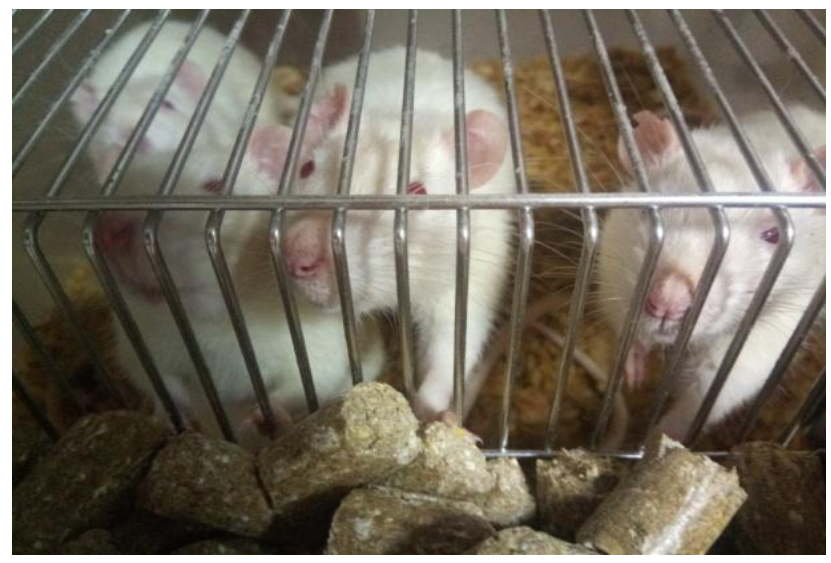

Turk ل Sport Exe 2019; 21(1):74-77

๑ 2019 Faculty of Sport Sciences, Selcuk University

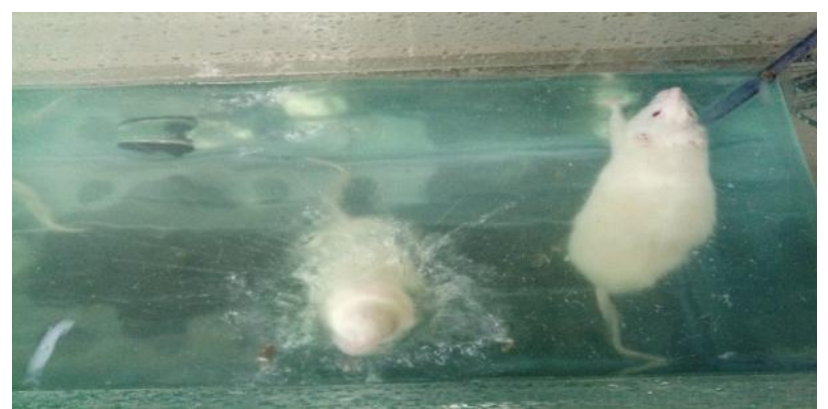

Figure 1-2. Working Group Photos

In the study, L-Carnitine $(1 \mathrm{gr} . / \mathrm{kg})$ was given to the rats in the form of liquid sublingually with the gavage method 3 times a week before starting the exercise. In the beginning of the study (1. day) before the exercise + L-Carnitine application, in the middle of the study (45th day) and finally at the end of the study (day 90), the weight measurements of the rats were recorded with precision weighing.
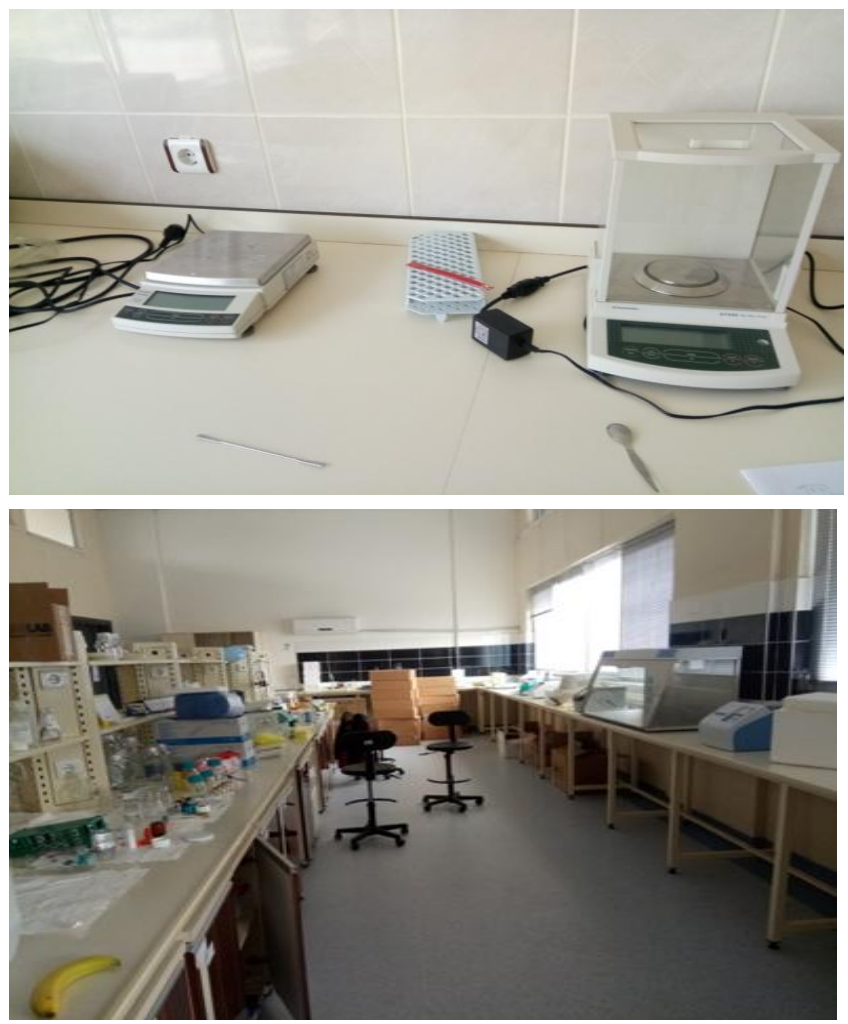

Figure 3-4. Photos for Data Collection Tools

The "IBM SPSS Statistics 22 analiz package program was used to evaluate the statistical analysis of the study. Normal distribution assumptions were evaluated with Kolmogorov-Smirnov and ShapiroWilk tests. In the rare cases where the two tests are contradictory, the Kolmogorov-Smirnov test result, which is more preferred in small data sets, was used. Type 1 error margin for normality tests is taken as 0.05 . In examining the time-dependent changes of the group; paired sample $t$ test was used. 


\section{INTERPRETATION OF ANALYSIS AND FINDINGS}

\begin{tabular}{|c|c|c|}
\hline $\begin{array}{l}\text { Tabl } \\
\text { Devi } \\
\text { Exer }\end{array}$ & $\begin{array}{l}\text { Weight M } \\
\text { of Old Obe } \\
\text {-Carnitine }\end{array}$ & $\begin{array}{l}\text { and } S t \\
\text { Using } R\end{array}$ \\
\hline Day & $\begin{array}{c}\text { Egzersiz+ } \\
\text { L-Carn. } \\
\text { G. (gr) }\end{array}$ & $\begin{array}{c}\text { (Std.) } \\
\text { (gr) }\end{array}$ \\
\hline 0. & 403.8571 & 4.75809 \\
\hline 45. & 400.1429 & 3.11241 \\
\hline 90. & 391.7143 & 3.98039 \\
\hline
\end{tabular}

\begin{tabular}{|c|c|c|c|c|c|c|c|c|c|}
\hline $\begin{array}{l}\text { Egzersiz+L- } \\
\text { Carnitine }\end{array}$ & Day & Mean & $\begin{array}{l}\text { Std. } \\
\text { Dev. }\end{array}$ & $\begin{array}{l}\text { Std. } \\
\text { Err. } \\
\text { Mean }\end{array}$ & Lower & Upper & $\mathrm{t}$ & $\mathrm{df}$ & $\begin{array}{l}\text { Sig.(2- } \\
\text { tailed) }\end{array}$ \\
\hline Pair 1 & 45.-0. & -3.71 & 5.25 & 1.98 & -8.57 & 1.14 & -1.87 & 6 & 0.110 \\
\hline Pair 2 & 90.45 . & -8.42 & 6.39 & 2.41 & -14.34 & -2.51 & -3.48 & 6 & 0.013 \\
\hline Pair 3 & 90.-0. & -12.14 & 5.52 & 2.08 & -17.24 & -7.03 & -5.82 & 6 & 0.001 \\
\hline
\end{tabular}

\section{CONCLUSION AND EVALUATION}

In Table 1 , the average of the weight of the exercise $+\mathrm{L}$-carnitine group of aged obese rats was determined as 0, 403,8571gr. According to this, the exercise of aged obese rats + L-carnitine group was found to lose weight regularly in every measurement in 3 months period.

In Table 2, in the paired samples, test results applied to determine the effect of time in exercise + L-carnitine group of elderly obese rats, no significant weight difference was found between day 0 and day 45 . ( $\mathrm{t} 6=-1,872, \mathrm{p}$ value $)=0.110$ ) According to this result; In the transition from day 0 to day 45 , the mean weight of rats was $-3,71429( \pm$ $1,98463) \mathrm{g}$, but there was no statistical significance. A statistically significant difference in weight was found between days 45 and day $90(\mathrm{t} 6=-3,485( \pm$ $2,41875) \mathrm{g}$, $\mathrm{p}$ value $=0,01$ ). In line with this result; In the transition from day 0 to day 45 , the mean weight of rats was $-8,42857( \pm 2,41875)$ g. A significant weight difference was determined between day 0 and day $90(\mathrm{t} 6=-5,820, \mathrm{p}$ value $=0,001)$. According to this result; In the transition from day 0 to day 90 , the mean weight of rats was $-12,14286( \pm 2,08656)$ gr.
According to these results, L-Carnitine, which is an amino acid derivative which activates fatty acids, has been found to provide support in every measurement in weight reduction of elderly obese rats when combined with regular exercise. In other words, elderly obese rats are approximately $3.5 \%$ of their weight in the first three months. have experienced a decline. If we adapt this result to people, a 65-year-old elderly and obese person will lose weight by $14 \%$ every one to three months if he / she gives a $3.5 \%$ weight to his / her own weight with regular exercise and L-Carnitine support every three months. In this way, it will be possible to get rid of obesity in a few years. Azuma T. et al. (2011) examined the effects of exercise training on the immune system, oxidative stress and weight in obese rats fed 42 high-fat diets and found that regular exercise resulted in favorable changes in oxidative stress and weight loss. This study is similar to our study. Moruguchi S. et al., A genetically obese Zucker, found significant changes in their sugar content and weight reduction, although they could not achieve a complete change in their immune system during 40-day exercise in mice. This study is similar to our study. 
As a result, L-Carnitine was found to lose weight in obese rats with regular exercise applied to elderly obese rats.

\section{Suggestions}

- Based on these results, elderly obese individuals may also be recommended to use LCarnitine in addition to regular exercise in order to lose weight.

- The incentives for regular exercise may be increased by the state to increase the quality of life of elderly obese individuals and to ensure a healthier and longer life.

- The only thing that will best support Lcarnitine supplementation to be used with regular exercise is careful nutrition. Therefore, in order to prevent weight gain in terms of quality of life in elderly obese individuals, necessary information support should be provided by doctors, specialists or physical education teachers.

\section{REFERENCES}

1. Adams SH., Hoppel CL., Lok KH., Zhao L., Wong S. W., et al. Plasma acylcarnitine profiles suggest incomplete long-chain fatty acid beta-oxidation and altered tricarboxylic acid cycle activity in type 2 diabetic African-American women. J. Nutr. 2009; 139, 1073-1081.

2. Artıs AS. The Relationship Between Proinflammatory Cytokines and Brain Natriuretic Peptide (Bnp) Level in Acute Intensive Exercise, (Unpublished Specialization Thesis), Erciyes University Faculty of Medicine, Department of Physiology, Kayseri, Turkey; 2009; 3, 5, 16, 17, 60.

3. Brownell KD, Wadden TA. Etiology and treatment of obesity: Towards understanding a serious, prevalent and refractory disorder. J Consult Clin Psychol, 1992; 60: 505-17.

4. Halliwell B. Free radicals and other reactive species in disease. In: Encyclopedia of life sciences. Ed: J. Wiley \& Sons; London: Nature Publishing Group; 2001; 1-7.

5. Hoppel CL, Genuth SM. Carnitine metabolism in normal-weight and obese human subjects during fasting. Am. J. Physiol. 1980; 238, E409-E415.

6. Hoppel CL. and Genuth SM. Urinary excretion of acetylcarnitine during human diabetic and fasting ketosis. Am. J. Physiol. 1982; 243, E168-E172.

7. Lee BJ, Lin JS, Lin YC, Lin PT. Effects of 1-carnitine supplementation on lipid profiles in patients with coronary artery disease. Lipids Health Dis. 2016; 15, 107.

8. Lindeboom L, Nabuurs CI, Hoeks J, Brouwers B, Phielix E. \& al. Long-echo time MR spectroscopy for skeletal muscle acetylcarnitine detection. J. Clin. Invest. 2014; 124, 4915-4925.

9. Odland LM, Heigenhauser GJ, Wong D, Hollidge-Horvat MG, Spriet LL. Effects of increased fat availability on fat-carbohydrate interaction during prolonged exercise in men. Am. J. Physiol. 1998; 274, R894-R902.
10. Roepstorff C, Halberg N, Hillig T, Saha AK, Ruderman NB. \& al. Malonyl-CoA and carnitine in regulation of fat oxidation in human skeletal muscle during exercise. Am. J. Physiol. Endocrinol. Metab. 2005; 288, E133-E142.

11. Saygin O. Investigation of Physical Activity Levels and Physical Fitness of 10.12 Years Old Children. Sipirdusa: PhD Thesis. Marmara University, Institute of Health Sciences. 2003.

12. Stone MH. Eating Disorders. Essentials of Strength Training and Contitioning. (Ed. Baechle TR). Canada: Human Kinetics. 1994; 238-239.

13. Yaprak Y. Effects of Aerobic and Strength Study on Oxygen Use and Cardiac Flow in Obese Women. Journal of Physical Education and Sport Sciences. 2004; II (2): 73-80.

14. Zhao G, Zhou S, Davie A, Su Q. Effects of moderate and high intensity exercise on T1/T2 balance. Exerc. Immunol. Rev. 2012; 18, 98-114. 